\title{
Hepatitis B, Hepatitis C and HIV among Children 6 to 59 Months in the Community in the Democratic Republic of Congo
}

\author{
Jeff Maotela Kabinda ${ }^{1,2,3}$, Tony Shindano Akilimali ${ }^{2}$, Ahuka Serge Miyanga ${ }^{1}$, \\ Philippe Donnen 4,5,6, Dramaix-Wilmet Michèle ${ }^{3,4,5}$ \\ ${ }^{1}$ Provincial Blood Transfusion Centre of Bukavu, Bukavu, Congo \\ ${ }^{2}$ Catholic University of Bukavu, Bukavu, Congo \\ ${ }^{3}$ Research Centre in Biostatistics and Epidemiology, Brussels, Belgium \\ ${ }^{4}$ Free University of Brussels, Brussels, Belgium \\ ${ }^{5}$ School of Public Health, Brussels, Belgium \\ ${ }^{6}$ Centre for Policy and Health Systems/International Health, Brussels, Belgium \\ Email: kabindaalu@yahoo.fr
}

Received 6 May 2015; accepted 13 June 2015; published 16 June 2015

Copyright (C) 2015 by authors and Scientific Research Publishing Inc.

This work is licensed under the Creative Commons Attribution International License (CC BY). http://creativecommons.org/licenses/by/4.0/

(c) (i) Open Access

\section{Abstract}

Objectives: To determine the prevalence of HBV, HCV and HIV among children 6 to 59 months and determine the risk factors. Materials and Methods: Descriptive and analytical study on children aged 6 to 59 months of community Maniema (DRC) conducted between 24 June and 24 July 2013. We enrolled 781 children aged 6 to 59 months. For association between the presence of viral markers and potential risk factors the chi-square test of Pearson was applied, the odds ratios (OR) and their $95 \%$ confidence intervals $(95 \%$ CIs) were calculated. The Fisher exact test was used when the conditions for application of the chi-square test of Pearson were not met. Results: The median age of the children was 34 months, $51 \%$ of female children. Ten percent of children had a history of blood transfusion; $6.6 \%$ and $64 \%$ had fever and anemia. The prevalence of HBsAg was $3.6 \%$, the prevalence of antibodies against hepatitis $\mathrm{C}$ was $2.8 \%$ and HIV was $3.7 \%$. The risk factors were HBsAg, male gender (5.5\% male vs $2.0 \%$ female; $O R=2.8(1.3-6.9) p=0.001$ ) and urban areas $(5.0 \%$ rural vs $0.5 \%$ urban, $O R=0.1(0.01-0.72), p=0.01)$. For HCV and HIV, these factors were the history of blood transfusion in the child and the mother. For HCV $7.6 \%$ of children with blood transfusion history; $O R=3.2(1.1-8.5) ; p=0.05$ and $11.1 \%$ history's mother blood transfusion, $O R=5.6(2.1-14.1)$. For HIV $11.4 \%$ of children with blood transfusion history, $O R=$ $3.8, \mathrm{p}=0.005$ and $9.8 \%$ history's mother blood transfusion, $\mathrm{OR}=2.9, \mathrm{p}=\mathbf{0 . 0 4}$. Conclusion: Vaccination against hepatitis $B$ in children must be widespread, educational messages to the population must target the risk factors for these viruses. A screening of hepatitis in pregnant women must be

How to cite this paper: Kabinda, J.M., Akilimali, T.S., Miyanga, A.S., Donnen, P. and Michèle, D.-W. (2015) Hepatitis B, Hepatitis $\mathrm{C}$ and HIV among Children 6 to 59 Months in the Community in the Democratic Republic of Congo. Open Journal of Pediatrics, 5, 171-178. http://dx.doi.org/10.4236/ojped.2015.52026 
coupled with rigorous selection policy for blood donors before each donation and qualification of any unit of blood.

\author{
Keywords \\ HBV, HCV, HIV, Child
}

\title{
1. Introduction
}

Chronic infection with the virus of hepatitis B virus (HBV) or C virus (HCV) affects more than 170 million people worldwide. It is considered a public health problem comparable to a silent epidemic [1] because of its risk of progression to cirrhosis and liver cancer. According to data from 2005 published in 2013, Central Africa, the prevalence of hepatitis $C$ was between $1.5 \%$ and 3.5\% [2] and in the age group of less than 5 years, the prevalence was $2.6 \%$. For hepatitis B, the prevalence in Central Africa varied between $5 \%$ and $7 \%$ in children 5 to 9 years [3]. HIV is the leading cause of child mortality in Africa, where 1700 children are newly infected every day [4] [5]. These three viruses share the same procedure for sending in children. HIV transmission in children is mainly through blood products and from mother to child. But the use of short course antiretroviral regimes in the third trimester allows for transmission rates $<5 \%$ [4]. For hepatitis B virus, outside the transmission by blood products [6] [7], the mother-to-child transmission remains the main infection diffusion modality in highly endemic countries, as is the case in sub-Saharan Africa [8]. This hepatitis B transmission rates from mother to child is estimated at between $40 \%$ and $45 \%$ [7]. For hepatitis C transmission in children is almost exclusively parenterally in Africa; while the risk of infection from mother to child is about $5 \%$, but it is possible only when the mother has chronic hepatitis $\mathrm{C}$ viremia [9]. The treatment of viral diseases in children remains a real problem in the context of our African countries with limited resources [7]. The point on which we can act effectively remains prevention. This can only be effective if the magnitude of the problem is known in our context. We conducted this study to make an inventory of the seroprevalence of hepatitis B, C and HIV in children 6 to 59 months and to assess the risk of transmission of these viruses in the child by blood products.

\section{Methodology}

\subsection{Part of the Study}

This is a descriptive and analytical cross-sectional study of children aged 6 to 59 months, from the period of 24 June to 24 July 2013 and conducted in two health zones of the city of Kindu (Kindu area and area health Alunguli), as well as in rural areas 2 (Kasongo and Kunda). These four health areas include 46 health areas in total but 38 easily accessible health areas were the subject of the investigation. A reasoned choice of four zones was made given the presence in these areas of the program for the prevention of transmission from mother to child of HIV and geographical accessibility. Kindu is the capital of Maniema province, in the center-east of the Democratic Republic of Congo. This province is one of 11 provinces of the DRC. The province has an area equal to $132250 \mathrm{~km}^{2}$. It has 2,038,471 inhabitants, with a density of 15 inhabitants $/ \mathrm{km}^{2}$. Maniema is divided into 18 health zones responsible for providing primary health care to the population, with the health structures of the 1st and 2nd level. These areas have a total of 274 health areas. However, in general, the proportion of health centers offering a minimum package of comprehensive activities is low. The general referral hospitals are underequipped and quality of complementary package of activities offered by these hospitals does not meet national standards.

\subsection{Study Population}

We conducted a household survey after research project has been approved by ethics committee of our university. We made the calculation of the number of households to deduct approximately the number of children under 5 years hoping to have at least one child of that age per household. The calculated sample size of 324 was based on a proportion of pregnant women with HIV to 3.5\% nationally [10] and an accuracy of $2 \%$. After multiplication by the effect of sampling by two, a total of 648 households was included. Sampling was done in several 
stages: the first step was to divide the households in 33 clusters (health area), each cluster containing at least 20 households. A selection of health areas (cluster) on the basis of a list of all the health areas of the 4 health zones drawn up in alphabetical order was carried out using a random selection proportional to population size health areas. The second step was to make a selection of villages/streets in the health areas selected in the first stage. After drawing up an alphabetical list of villages or avenues, a random draw proportional to the size of the population of the villages/avenues has been achieved. Thus 138 villages were selected representing $12 \%$ of all villages/streets. The number of households to be surveyed in the villages/avenues selected was obtained by dividing the number of required households (20 households) by the number of avenues/villages selected. The investigation team consisted of 4 people per health area: the supervising physician, a nurse, a laboratory technician and a plot of reliever recruited in the community. The investigation team visited the village center/avenues selected and chose a direction at random following the pen tip tossed and applied a systematic sampling type: in the selected travel direction The first household was the one that matched the random number drawn between 1 and the sampling interval was determined by the number of households in the village (known in advance by the plot reliever) divided by the number of households to be surveyed. The selection thus increased from household to household by adding the sampling interval $\mathrm{k}$ in the household corresponding number last visited up to the number of households required for this village/this avenue. From this set we selected the households that had a child from 6 to 59 months and who have freely agreed to participate in the survey. Thus we have reached 781 children aged 6 to 59 months. We studied the following parameters: the age of the child, gender, MUAC, fever defined by an axillary temperature above $38^{\circ} \mathrm{C}$, anemia defined by hemoglobin levels below $11 \mathrm{~g} / \mathrm{dl}$. The value of hemoglobin was obtained by the HemoCueR device. We also noted the state of conjunctiva, the presence of edema, blood transfusion history in the past 12 months, the level of education of the mother, the maternal age, the antecedent of transfusion in the mother during pregnancy, HBV serology results, Anti-HIV and anti-HCV. Aspects ethics were complied in sens, the study participation was voluntary after a clear explanation and verbal approval was obtained.

\subsection{Serology}

Serodiagnosis on each sample was taken from the following reagents: a) Determine TM HBV HBsAg, Inverness Medical Japan Ltd.; b) HCV Orgenics Ltd., Medical Innovations Group, Israel c) HIV: HIV-Determine TM half Abbott.

\subsection{Statistical Analysis}

We encoded the data using SPSS 20. Some variables taken into account in the analysis were categorized age of the child in months in 3 categories (between 6 and 12 months, between 13 and 24 months and between 25 and 59 months) for the descriptive analysis but into two groups for the univariate analysis: less than 24 months and over 24 months, sex, social background in both rural and urban groups, the MUAC into 3 categories (less than $11 \mathrm{~cm}$, between 11 and $12.5 \mathrm{~cm}$ and $12.5 \mathrm{~cm}$ ), the mother's level of education into 4 categories (none, primary, secondary and higher) and then two groups in the univariate analysis: and without education, age of the mother in four categories for the description of the sample (20 years and under, 21 to 30 years, between 31 and 40 years and over 40 years) and then into two groups for the following analyzes: 30 years old, over 30 years. The usual descriptive statistical analysis consisted of proportions for categorical variables, median, minimum and maximum for the age of the child and the mother's age. To analyze the association between the presence of viral markers and potential risk factors the chi-square test of Pearson was applied, the odds ratios (OR) and their 95\% confidence intervals (95\% CIs) were were calculated. The Fisher exact test was used when the conditions for application of the chi-square test of Pearson were not met. The statistical significance chosen was $\mathrm{p}<0.05$.

\section{Results}

The median age of children in our sample was 34 months, more than half are found in the age group of 25 - 59 months. The proportion of girls is slightly higher than that of boys. $3 / 4$ of the sample are from rural areas. Ten percent of the children had had a blood transfusion during the 12 months preceding the survey. When passing investigators $6.6 \%$ of children had fever, $64 \%$ were anemic and $9.2 \%$ had edema of the lower limbs (Table 1 ). Furthermore $9.3 \%$ of mothers of children were transfused during pregnancy of the child. The median age of the 
Table 1. General children 6 to 59 months of Maniema province in 2013.

\begin{tabular}{|c|c|c|c|}
\hline & $\mathbf{n}$ & $\%$ & Me (min-max) \\
\hline Child's age (in months) & 781 & & $34(6-59)$ \\
\hline $06-12$ & & 15.1 & \\
\hline $13-24$ & & 33.2 & \\
\hline $25-59$ & & 51.7 & \\
\hline Sex of child & 781 & & \\
\hline male & & 49.0 & \\
\hline female & & 51.0 & \\
\hline Original middle & 781 & & \\
\hline urban & & 28.4 & \\
\hline rural & & 71.6 & \\
\hline Arm circumference $(\mathrm{cm})$ & 699 & & \\
\hline$<11.0$ & & 72.1 & \\
\hline 11.0 to 12.5 & & 4.3 & \\
\hline$>12.5$ & & 23.6 & \\
\hline Mother Study level & 781 & & \\
\hline primary & & 20.2 & \\
\hline secondary & & 51.0 & \\
\hline University & & 14.1 & \\
\hline without & & 14.7 & \\
\hline Age of mother (in years) & 781 & & $31.0(16-50)$ \\
\hline$\leq 20$ & & 14.2 & \\
\hline $21-30$ & & 47.0 & \\
\hline $31-40$ & & 26.2 & \\
\hline$>40$ & & 12.6 & \\
\hline fever & 707 & 6.6 & \\
\hline anemia & 644 & 63.6 & \\
\hline Conjunctiva pale eyelid & 778 & 7.5 & \\
\hline Swelling of lower limbs & 723 & 9.2 & \\
\hline Transfusion history of the last 12 months & 781 & 10.3 & \\
\hline History of transfusion for the mother when the child's pregnancy & 781 & 9.3 & \\
\hline
\end{tabular}

Me $=$ median, Min = Minimum and $\max =$ maximum .

mothers was 31 years, $14 \%$ were under 20 years old while 15\% had not studied and 51\% had a secondary level of study as shown in Table 1.

The seroprevalence of hepatitis B in children 6 to 59 months was 3.6\% (95\% CI 2.6 to 5.3). The seroprevalence of HBV surface antigen differed statistically significantly by gender $(\mathrm{p}=0.001)$ and the place of origin ( $\mathrm{p}$ $=0.01$ ). It was observed a higher proportion of presence of the surface antigen of hepatitis B among male children $(\mathrm{OR}=2.8)$ and among rural children $(5.0 \%)$. The risk of the hepatitis $\mathrm{B}$ antigen was also increased for 
children with a history of blood transfusion and those whose mothers had been transfused during pregnancy (Table 2).

The presence of blood transfusion history in the mother and in children is associated with a statistically significant risk of positivity of antibodies to hepatitis C. The overall seroprevalence of HCV was $2.8 \%$ (95\% 1.8 to 4.3) (Table 3). The seroprevalence of anti-HCV was $7.6 \%$ in children who were transfused against $2.5 \%$ in those who did not. The proportion of children with antibodies against hepatitis $C$ was $11 \%$ in children whose mothers had been transfused against $2.2 \%$ in children without transfusion history in their mothers. Strong but not statistically significant association $(\mathrm{p}=0.08)$ was observed between the mid and hepatitis $\mathrm{C}$.

We found a child with a co-infection of HIV-HCV three viruses HBV, two had co-infected hepatitis B and C, a child had HIV and hepatitis B co-infection and another child had a co-infection HIV and hepatitis C. HIV seroprevalence was 3.7\% (95\% CI 2.6 to 5.3) (Table 4).

We did not observe significant difference in HIV prevalence in children based on the following variables: age and sex of the child; the place of origin, age and level of mother study. As against the proportion of HIV was statistically significantly higher in children with a history of blood transfusion or for either himself or with his mother (Table 4).

Table 2. Seroprevalence of hepatitis B and its determinants in children 6 to 59 months.

\begin{tabular}{|c|c|c|c|}
\hline & $\mathrm{HBV}+\%$ & OR (IC à 95\%) & $\mathrm{p}$ \\
\hline Total (776) & 3.6 & & \\
\hline Child's age (in months) & & & 0.58 \\
\hline$\leq 24(\mathrm{n}=359)$ & 3.3 & $0.8(0.0-1.7)$ & \\
\hline$>24(n=390)$ & 4.1 & 1 & \\
\hline Sex of child & & & 0.001 \\
\hline Male $(n=361)$ & 5.5 & $2.8(1.3-6.9)$ & \\
\hline Female $(\mathrm{n}=398)$ & 2.0 & 1 & \\
\hline Original environment & & & 0.01 \\
\hline Urban $(\mathrm{n}=197)$ & 0.5 & $0.1(0.01-0.72)$ & \\
\hline Rural (n = 541) & 5.0 & 1 & \\
\hline Mother Study level & & & $0.70^{*}$ \\
\hline Without $(\mathrm{n}=113)$ & 2.6 & $0.6(0.1-2.0)$ & \\
\hline Instruction $(n=624)$ & 4.0 & 1 & \\
\hline Age of mother (in years) & & & 0.70 \\
\hline$\leq 30(\mathrm{n}=468)$ & 4.0 & $1.2(0.5-2.7)$ & \\
\hline$>30(\mathrm{n}=258)$ & 3.5 & 1 & \\
\hline Transfusion of the child the last 12 months & & & $0.34^{*}$ \\
\hline Yes $(n=76)$ & 6.6 & $1.9(0.6-4.8)$ & \\
\hline No $(n=608)$ & 3.6 & 1 & \\
\hline Transfusion of the parent on the child's pregnancy & & & $0.63^{*}$ \\
\hline Yes $(n=70)$ & 5.7 & $1.5(0.4-4.2)$ & \\
\hline No $(n=614)$ & 3.9 & 1 & \\
\hline
\end{tabular}

${ }^{*}$ Fisher exact. 
Table 3. Seroprevalence of hepatitis $C$ and its determinants in children 6 to 59 months.

\begin{tabular}{|c|c|c|c|}
\hline & $\mathrm{HCV}+\%$ & OR (IC à 95\%) & $\mathrm{p}$ \\
\hline Total (744) & & & \\
\hline Child's age (in months) & & & 0.65 \\
\hline$\leq 24(\mathrm{n}=299)$ & 2.7 & $0.8(0.3-1.9)$ & \\
\hline$>24(\mathrm{n}=399)$ & 3.3 & 1 & \\
\hline Sex of child & & & 0.41 \\
\hline Male $(n=366)$ & 3.3 & $1.4(0.5-3.5)$ & \\
\hline Female $(\mathrm{n}=383)$ & 2.3 & 1 & \\
\hline Original environment & & & 0.08 \\
\hline Urban $(\mathrm{n}=208)$ & 4.8 & $2.3(0.9-5.4)$ & \\
\hline Rural (n = 508) & 2.2 & 1 & \\
\hline Mother Study level & & & $0.75^{*}$ \\
\hline Without $(\mathrm{n}=111)$ & 1.8 & $0.6(0.1-2.5)$ & \\
\hline Instruction (n = 603) & 3.2 & 1 & \\
\hline Age of mother (in years) & & & 0.79 \\
\hline$\leq 30(\mathrm{n}=402)$ & 2.9 & $0.9(0.4-2.2)$ & \\
\hline$>30(n=270)$ & 3.3 & 1 & \\
\hline Transfusion of the child the last 12 months & & & $0.05^{*}$ \\
\hline Yes $(n=79)$ & 7.6 & $3.2(1.1-8.5)$ & \\
\hline No $(n=610)$ & 2.5 & 1 & \\
\hline Transfusion of the parent on the child's pregnancy & & & $0.001^{*}$ \\
\hline Yes $(\mathrm{n}=72)$ & 11.1 & $5.6(2.1-14.1)$ & \\
\hline No $(n=602)$ & 2.2 & 1 & \\
\hline
\end{tabular}

*Fisher exact.

Table 4. Prevalence of HIV infection and its determinants in children 6 to 59 months.

\begin{tabular}{|c|c|c|c|}
\hline & $\mathrm{HIV}+\%$ & OR (IC à 95\%) & $\mathrm{p}$ \\
\hline Total (778) & & & \\
\hline Child's age (in months) & & & 0.97 \\
\hline$\leq 24(\mathrm{n}=328)$ & 3.9 & $1.0(0.5-2.1)$ & \\
\hline$>24(\mathrm{n}=399)$ & 4.0 & 1 & \\
\hline Sex of child & & & 0.26 \\
\hline Male $(n=361)$ & 4.7 & $1.5(0.7-3.3)$ & \\
\hline Female $(\mathrm{n}=383)$ & 3.1 & 1 & \\
\hline Original environment & & & 0.22 \\
\hline Urban $(n=201)$ & 2.5 & $0.5(0.2-1.4)$ & \\
\hline Rural (n = 541) & 4.4 & 1 & \\
\hline Mother Study level & & & $0.99^{*}$ \\
\hline Without $(\mathrm{n}=114)$ & 3.5 & $0.8(0.3-2.6)$ & \\
\hline Instruction $(n=636)$ & 3.9 & 1 & \\
\hline Age of mother (in years) & & & 0.3 \\
\hline$\leq 30(\mathrm{n}=411)$ & 3.6 & $0.7(0.3-1.4)$ & \\
\hline$>30(\mathrm{n}=264)$ & 5.3 & 1 & \\
\hline Transfusion of the child the last 12 months & & & $0.005^{*}$ \\
\hline Yes $(\mathrm{n}=79)$ & 11.4 & $3.8(1.6-8.7)$ & \\
\hline No $(n=618)$ & 3.2 & 1 & \\
\hline Transfusion of the parent on the child's pregnancy & & & $0.04^{*}$ \\
\hline Yes $(n=71)$ & 9.8 & $2.9(1.1-7.1)$ & \\
\hline No $(\mathrm{n}=625)$ & 3.5 & 1 & \\
\hline
\end{tabular}

*Fisher exact. 


\section{Discussion}

In our study on hepatitis B, C and HIV in children between 6 and 59 months, the prevalence of hepatitis B was 3.6\%, hepatitis C and HIV 2.8\% and 3.7\%. This study has some methodological limitations. Indeed, our study population was taken from the community and the calculation of proportions ignored vaccinations against hepatitis previously received by the children. These two reasons might be that there under-or overestimation of different prevalences. In addition the calculation of proportion did not take into account the effect of cluster sampling which may impact on confidence intervals and p-values. However, despite these reservations, this study has achieved its objectives: to estimate the prevalence of the three viruses in the age group 6 to 59 months and identify risk factors in our context.

The frequency of chronic carriers of hepatitis B surface antigen found in our study is higher than that found in Egypt $0.38 \%$ [11] but lower than projected estimates for the age group 0 to 4 years Central Africa [3] which were between $4 \%$ and $5 \%$. The male children (OR 2.8) and children from rural areas (OR $=10)$ were more exposed respectively from the female children and those from urban areas. For sex the result is different from that found in Egypt but the result is similar to that found in Laos. [12] Regarding the environment from Mao et al. in Cambodia [13] and in Egypt Iman et al. [14] found similar results to ours. We did not find any plausible explanation in the literature for this. However, in rural areas the viral infection prevention measures are less present than in urban areas. Our study found no statistically significant association between seropositivity to HBsAg and blood transfusion history, this differs results of other studies in Egypt and Brazil [14] [15]. Indeed the infectivity of HBV is related to the presence of virus in most biological liquids infectious titers often very high, up to 109 virus/ml (blood, exudates, genital secretions mainly) [6] [7] for the three contamination routes: blood, sex and mother to child. The first route (blood) became less and less common in developed countries through the rigorous screening for all blood but in the countries of sub-Saharan Africa the risk remains high.

The main risk factors for viral hepatitis C identified in our study are the history of blood transfusion in the child and the mother. Egypt Gamal et al. [11] also found blood transfusion as a risk factor for HCV as Fafri Pakistan et al. [16] Apart from that, Gamal et al. also observed that the tattoo and surgery were risk factors for hepatitis C. But be aware that HCV infection is less common in children than in adults , and natural history, prognosis and clinical significance of HCV infection in childhood is based on estimates [11] [17] [18]. It is recognized that spontaneous clearance of the virus is possible but curing date is not determinable and prognostic factors are currently not known. [9] In children infected with HCV vertical transmission by up to $24 \%$ of spontaneous resolutions have been described before age 2 years but less than $2.5 \%$ after that age. [19] The spontaneous resolution rate the highest (up to 45\%) is described in children who received postnatal transfusion [19] [20]. Anyway, the treatment of a viral infection with hepatitis $C$ is not within the reach of people in sub-Saharan Africa or in cost or monitoring. Mortada et al. [21] estimated the cost at 7500 Euros per year to control infection and improve the quality of life of patients who suffer.

HIV prevalence observed in our study is similar to that of the general population of the country [10] and slightly higher than that observed in the population of blood donors $2.9 \%$ [22]. As for hepatitis C, the risk factors of HIV in children is the history of blood transfusion in the child and the mother. The mother-child transmission of HIV (HIV) has become a rare event in the most economically advantaged countries [4] and low frequency in countries with lower income. The weakness of the transmission of HIV from mother to child is achieved by routine screening in all pregnant women, monitoring and medical care for mothers and newborns. In all these measures, there are the strategies related to the mode of feeding among women living with HIV as they aim to reduce the risk of HIV transmission from mother to child as [5].

\section{Conclusion}

The seroprevalence of viral markers is a reflection of the prevalence gives an idea about the problem state. The weight of infections of hepatitis B, C and HIV are real in children as in adults. Blood transfusion remains a means of transmission of hepatitis and HIV in our midst. These infections are preventable, should be put in place for all vaccination against HBV, education of the population and screening of pregnant mothers hope for reducing the incidence of hepatitis in children. It should also strengthen the blood donor selection and qualification measures of all blood unit for secure blood products. 


\section{References}

[1] Debbeche, R., Said, Y., Ben Temime, H., El Jery, K., Salem, S.B.M. and Najjar, T. (2013) Epidemiology of Hepatitis $\mathrm{C}$ in Tunisia. The Tunisia Medicale, 91, 86-91.

[2] Hanafiah, K.M., Groeger, J., Flaxman, D.A. and Wiersma, S.T. (2013) Global Epidemiology of Hepatitis C Virus Infection: New Estimates of Age Specific-Antibody to HCV Seroprevalence. Hepatology, 57, 1333-1342.

[3] Otta, J.J., Stevensa, G.A., Groegerb, J. and Wiersmaa, S.T. (2012) Global Epidemiology of Hepatitis B Virus Infection: New Estimates of Age-Specific and HBsAg Seroprevalence Endemicity. Vaccine, 30, 2212-2219. http://dx.doi.org/10.1016/j.vaccine.2011.12.116

[4] Becquet, R. and Leroy, G. (2007) The Challenges Raised by the Prevention of Mother-Child Transmission of HIV in Africa. Medical Press, 36, 1947-1957. http://dx.doi.org/10.1016/j.lpm.2007.02.031

[5] Tabone, M.D., Vaudre, G., Dehée, A. and Dollfus, C. (2005) Maternal-Fetal Transmission of HIV: Progress and Prospects. Archives of Pediatrics, 12, 1-3. http://dx.doi.org/10.1016/j.arcped.2004.11.007

[6] Cadranel, J.F., Caron, C., Collot, G., Van Batten, C. and Dumouchel, P. (1999) Hepatitis B Epidemiology, Natural History, Biology, Treatment Monitoring. Biology Pathology, 47, 917-927.

[7] Ranger Rogez, S., Alain, S. and Denis, F. (2002) Hepatitis Viruses: MTCT. Pathology Biology, 50, 568-575.

[8] Singh, A.E., Plitt, S.S., Osiowy, C., Surynicz, K. and Kouadjo, E. (2011) Factors Associated with Vaccine Failure and Vertical Transmission of Hepatitis B among a Cohort of Mothers and Infants Canadian. Journal of Viral Hepatitis, 18, 468-473. http://dx.doi.org/10.1111/j.1365-2893.2010.01333.x

[9] Lacaille, F. (2002) Chronic Hepatitis C in Children. Pediatrics Archive, 9, 539-542.

[10] National Plan to Combat AIDS (NSP) 2014-2017, Ministry of Health, DRC, Kinshasa 2013.

[11] Esmat, G., Hashem, M., El-Raziky, M., El-Akel, W., El-Naghy, S., El-Koofy, N., et al. (2012) Risk Factors for Hepatitis C Virus Acquisition and Predictors of Persistence among Egyptian Children. Liver International, 32, 449-456.

[12] Xeuatvongsa, A., Komada, K., Kitamura, T., Vongphrachanh, P., Pathammavong, C., Phounphenghak, K., et al. (2014) Chronic Hepatitis B Prevalence among Children and Mothers: Results from a Nationwide, Population-Based Survey in Lao People’s Democratic Republic. PLoS ONE, 9, e88829.

[13] Mao, B., Patel, M.K., Hennessey, K., Duncan, R.J., Wannemuehler, K. and Soeung, S.C. (2013) Prevalence of Chronic Hepatitis B Virus Infection after Implementation of a Hepatitis B Vaccination Program among Children in Three Provinces in Cambodia. Vaccine, 31, 4459-4464.

[14] Salama, I.I., Sami, S.M., Salama, S.I., Said, Z.N., Rabah, T.M. and Abdel-Mohsin, A.M. (2013) Hepatitis B Virus Infection among Egyptian Children Vaccinated during Infancy. International Journal of Medical, Health, Biomedical and Pharmaceutical Engineering, 7, 554-561.

[15] Compri, A.P., Miura, I., Porta, G., Lemos, M.F., Saraceni, C.P. and Moreira, R.C. (2012) Hepatitis B Virus Infection in Children, Adolescents, and Their Relatives: Genotype Distribution and Precore and Core Gene Mutations. Revista da Sociedade Brasileira de Medicina Tropical, 45, 301-304. http://dx.doi.org/10.1590/S0037-86822012000300004

[16] Jafri, W., Jafri, N., Yakoob, J., Islam, M., Tirmizi, S.F.A., Jafar, T., et al. (2006) Hepatitis B and C: Prevalence and Risk Associated with Seropositivity Factoring among Children in Karachi, Pakistan. BMC Infectious Diseases, 6, 101. http://dx.doi.org/10.1186/1471-2334-6-101

[17] Kelly, D. and Skidmore, S. (2002) Hepatitis C-Z: Recent Advances. Archives of Disease in Childhood, 86, $339-343$. http://dx.doi.org/10.1136/adc.86.5.339

[18] Zein, N.N. (2007) Hepatitis C in Children: Recent Advances. Current Opinion in Pediatrics, 19, 570-574. http://dx.doi.org/10.1097/MOP.0b013e3282f04ea8

[19] Martin, S.R. (2009) Hepatitis C in Children. Pediatrics Archive, 16, 715-716.

[20] Vogt, M., Lang, T., Frösner, G., Klingler, C., Sendl, A.F., Zeller, A., et al. (1999) Prevalence and Clinical Outcome of Hepatitis C Infection in Children Who Underwent Cardiac Surgery before the Implementation of Blood-Donor Screening. New England Journal of Medicine, 341, 866-870. http://dx.doi.org/10.1056/NEJM199909163411202

[21] El-Shabrawi, M.H. and Kamal, N.M. (2013) Burden of Pediatric Hepatitis C. World Journal of Gastroenterology, 19, 7880-7888. http://dx.doi.org/10.3748/wjg.v19.i44.7880

[22] Nzaji, M.K. and Ilunga, B.K. (2013) A Study of the Prevalence of Infectious Markers in Blood Donors in Rural Areas. The Case of Kamina Hospital. Santé Publique, 25, 213-217. 